3 Hendel J, Nyfors A. Impact of methotrexate therapy on the folate status of psoriatic patients. Clin Exp Dermatol 1985;10:30-5.

4 Dodd HJ, Kirby JDT, Munro DD. Megaloblastic anaemia in psoriatic patients treated with methotrexate. Br $\mathcal{Y}$ Dermatol 1985;112:630.

5 Lawrence CM, Dahl MGC. Two patterns of skin ulceration induced by methotrexate in patients with psoriasis. I Am Acad Dermatol 1984;11:1059-65.

(Accepted 27 fuly 1987)

Department of Dermatology, Royal Liverpool Hospital, Liverpool L7 8XP

HW K NG, MB, CHB, senior house officer

A W MACFARLANE, MRCP, registrar

R M GRAHAM, MRCP, senior registrar

J L VERBOV, MD, FRCP, consultant dermatologist

Correspondence to: Dr Macfarlane.

\section{Undescended testes in low birthweight infants}

Cryptorchidism is a known risk factor for infertility and testicular malignancy. The reported incidence is rising and is now over $2 \%,{ }^{1}$ bilateral abnormality occurring in $10-25 \%$ of cases. Undescended testes are more common in low birthweight infants, ${ }^{2}$ but there is little detailed information on this subgroup. We collected extensive data on preterm infants, enabling us to determine the incidence of cryptorchidism and its associations.

\section{Patients, methods, and results}

Altogether 355 male infants with birth weights under $1850 \mathrm{~g}$ who had been admitted to Cambridge, Norwich, Ipswich, or Kings Lynn in 1982 or 1983 and all units in East Anglia in 1984, were examined by one of us (RM) at 18 months after term. An undescended testis was defined as one that could not be brought down to the bottom of the scrotum by manipulation (alternatively, a previous operative diagnosis was taken).

The overall incidence of undescended testes was 35/355 (9.9\%). Cryptorchidism was strongly related to birth weight (table). In infants below and above $1500 \mathrm{~g}$ the incidence was $29 / 186(16 \%)$ and $6 / 169(3.6 \%)$, respectively $(p=0.001)$ Bilateral abnormality occurred in 15 of the 35 cases $(43 \%)$. Of the 260 infants born at up to 32 weeks' gestation, $33(13 \%)$ had undescended testes compared with two of the $95(2 \%)$ born after 32 weeks $(p<0.01)$. A birth weight of under $1850 \mathrm{~g}$ was the criterion for entry to this study; thus larger infants born after 31 weeks were excluded. Undescended testes were, however, unrelated to being small for gestational age.

Extensive data on antenatal, perinatal, and postnatal factors, collected in a subgroup of 287 infants enrolled in a preterm feeding trial, ${ }^{3}$ showed significant associations between undescended testes and both necrotising enterocolitis $(p=0.025)$ and eczema at 18 months $(p=0.001 ;$ table) (enterocolitis and eczema were evenly distributed across the range of birth weight). Cryptorchidism tended to be more common in infants whose mothers had been given steroids $(8 / 44(18 \%)$ compared with $21 / 243(8 \cdot 6 \%) ; p=0 \cdot 053)$. No significant associations were found with maternal age or parity, conception while the mother was taking oestrogens, breech delivery, phototherapy (which affects plasma luteinising hormone concentration ${ }^{4}$, severity of neonatal respiratory disease, or any other factor analysed.

\section{Comment}

Cryptorchidism emerges as one of the commonest abnormalities in surviving male infants of very low birth weight, occurring in $19 \%$ of those weighing below $1000 \mathrm{~g}$. Testicular descent, normally a late fetal event, may be interrupted by preterm birth; interestingly, in infants born after 32 weeks' gestation the incidence of cryptorchidism was similar to that reported in infants born at term.
Incidence of undescended testes by birth weight and presence of necrotising enterocolitis and eczema 18 months after term

\begin{tabular}{lccc}
\hline & $\begin{array}{c}\text { No with } \\
\text { normally descended } \\
\text { testes }\end{array}$ & $\begin{array}{c}\text { No }(\%) \text { with } \\
\text { undescended } \\
\text { testes }\end{array}$ & Significance* \\
\hline Birth weight (g): & 29 & $7(19)$ & $\mathrm{p}<0.001$ \\
$\quad \leqslant 999$ & 34 & $7(17)$ & \\
$1000-1199$ & 59 & $9(13)$ & \\
$1200-1399$ & 75 & $7(9)$ & \\
$1400-1599$ & 123 & $5(4)$ & \\
$1600-1849$ & 250 & $25(9)$ & $\mathrm{p}=0.025$ \\
Necrotising enterocolitist: & 8 & $4(33)$ & \\
None & 224 & $20(8)$ & $\mathrm{p}=0.001$ \\
Present & 31 & $7(18)$ & \\
Eczema at 18 month examinationt: & 1 & $2(67)$ & \\
$\quad$ None & & & \\
Mild or moderate & & &
\end{tabular}

${ }^{2}$ Test, one degree of freedom for trend.

tInfants enrolled in preterm feeding trial.

We failed to find an association between undescended testes and factors described previously. ${ }^{1}$ The association between undescended testes and necrotising enterocolitis may be a chance finding, given that multiple factors were analysed, but intra-abdominal disease might interfere with testicular descent. The association with eczema is probably not a chance finding Given the trend towards a higher incidence of cryptorchidism in the small group whose mothers received steroids, we speculate that cutaneous absorption of corticosteroid creams for infantile eczema may interfere with the descent of testes.

We calculate that an increase in the survival of infants weighing under $1500 \mathrm{~g}$ from $50 \%$ to $80 \%$ (as occurred in Cambridge during 1952-82) would increase the incidence of undescended testes in the population by only $0.04 \%$, which does not account for the reported secular rise from around $1 \%$ to $2 \%$.

The risk of testicular malignancy is reportedly up to 50 times higher in cryptorchid men. ${ }^{5}$ Bilateral abnormality, which may increase the risk of malignancy, was common in low birthweight infants (43\%), further raising their theoretical risk of later testicular cancer. The benefits of early orchidopexy in improving fertility and preventing malignancy remain uncertain. We suggest, however, that cryptorchidism should be sought at routine follow up of preterm infants and that long term epidemiological surveillance of cryptorchid infants born before term is required

We thank Mr B A Baker for technical help; Mr R H Whitaker for helpful comments; and Farley Health Products Ltd and East Anglian Regional Health Authority for financial help (RM).

Swerdlow AJ, Wood KH, Smith PG. A case control study of the aetiology of cryptorchidism. 7 Epidemiol Community Health 1983;37:238-44.

Scorer CG, Farrington HG. Congenital deformities of the testis and epididymis. London: Butterworths, 1971.

3 Lucas A, Gore SM, Cole TJ, et al. A multicentre trial on the feeding of low birthweight infants: effects of diet on early growth. Arch Dis Child 1984;59:722-30.

4 Dacou-Vouletakis C, Anaghnostakis D, Maisaniotis N. Effect of prolonged illumination (phototherapy) on concentrations of luteinising hormone in human infants. Science 1978;199:1229-31. 5 Martin DC. Malignancy in the cryptorchid testis. Urol Clin North Am 1984;9:371-6.

(Accepted 26 fune 1987)

Medical Research Council Dunn Nutrition Unit and University Department of Paediatrics, Cambridge

R MORLEY, MB, BCHIR, clinical scientist

A LUCAS, MA, MRCP, Medical Research Council clinical scientific staff, honorary consultant paediatrician

Correspondence to: Dr R Morley, Dunn Nutritional Laboratory, Cambridge CB4 1XJ. 